\title{
HUBUNGAN ANTARA POLA TIDUR DENGAN PRESTASI BELAJAR
}

\author{
Yohana Intan Dili Susanti
}

Surel: yhnintan13@gmail.com

\begin{abstract}
The purpose of this study was to determine the relationship between sleep patterns with learning achievement. This research was conducted at SD Negeri Babad 1 with the number of 31 students consisting of grade 4 and class 5. The research type used is cross sectional survey. Instruments used in the form of rating scale and document studies. Data were analyzed using descriptive study. The results of this study indicate that: students who have good sleep patterns and achievements are also good number of more that 18 students (58\%) compared with students who have good sleep patterns but the learning achievement is enough that is 8 students (26\%). However, some have poor sleep patterns. Students with learning achievement that is enough more number that is 4 student (13\%) compared with student having good learning achievement there is only 1 student (3\%).
\end{abstract}

Keywords: Sleep patterns, Learning achievement.

\begin{abstract}
ABSTRAK
Tujuan dari penelitian ini adalah untuk mengetahui hubungan antara pola tidur dengan prestasi belajar. Penelitian ini dilakukan di SD Negeri Babad 1 dengan jumlah siswa 31 yang terdiri dari kelas 4 dan kelas 5 . Jenis penelitian yang dipakai adalah cross sectional survey. Instrumen yang digunakan berupa skala rating dan studi dokumen. Data dianalisis dengan menggunakan studi deskriptif. Hasil penelitian ini menunjukkan bahwa: siswa yang memiliki pola tidur yang baik dan prestasinya juga baik jumlahnya lebih banyak yaitu 18 siswa (58\%) dibandingkan dengan siswa yang memiliki pola tidur baik tetapi prestasi belajarnya cukup yaitu 8 siswa (26\%). Namun, ada pula yang memiliki pola tidur yang kurang baik. Siswa dengan prestasi belajar yang cukup lebih banyak jumlahnya yaitu 4 siswa (13\%) dibandingkan dengan siswa yang memiliki prestasi belajar baik hanya ada 1 siswa $(3 \%)$.
\end{abstract}

Kata Kunci: Pola tidur, Prestasi belajar.

\section{PENDAHULUAN}

Tidur merupakan suatu kebutuhan yang penting untuk tubuh kita. Karena dengan tidur, kita bisa mengistirahatkan tubuh setelah lelah beraktivitas seharian. Satu orang dengan yang lainnya pasti memiliki kebutuhan tidur yang berbeda-beda. Apabila semakin tinggi tingkat perkembangan, maka akan semakin berkurang jumlah kebutuhan tidur.
Untuk usia anak sekolah (6-12 tahun) dibutuhkan waktu tidur selama 10 jam. Anak yang tidak memiliki waktu istirahat yang cukup, akan mempengaruhi aktivitas sehari-hari. Salah satu aktivitas yang rutin dilakukan oleh pelajar khususnya anak usia sekolah adalah belajar.

Memiliki pola tidur yang kurang baik akan mempengaruhi kesehatan. Anak akan mudah merasa 
lelah dan jika pola tidurnya tidak dirubah bisa menyebabkan daya tahan tubuhnya menurun. Namun, bukan hanya berpengaruh pada kesehatan saja tetapi juga berpengaruh pada perilaku. Anak menjadi hiperaktif, tidak konsentrasi dalam belajar, dan memiliki masalah pada perilaku baik di sekolah maupun di rumah.

Berdasarkan penelitian yang telah dilakukan oleh Panangian $\mathrm{P}$. Marpaung, Siantan Supit, dan Joice Nancy (2013) menunjukkan bahwa pada umumnya, siswa yang cukup tidur memiliki prestasi belajar yang tinggi yaitu sebesar $49,1 \%$. Tingkat prestasi belajar siswa kelas 3 di SMA Binsus Manado masuk dalam kategori memuaskan. Penelitian sebelumnya melatarbelakangi peneliti untuk mengetahui apakah ada hubungan antara pola tidur terhadap prestasi belajar anak usia Sekolah Dasar, serta melihat faktor mengapa hubungan tersebut dapat mempengaruhi prestasi belajar anak usia Sekolah Dasar.

\section{METODE PENELITIAN}

Jenis penelitian yang digunakan adalah studi deskriptif yaitu penelitian yang diarahkan untuk mengetahui hubungan antara pola tidur dengan prestasi belajar siswa. Dengan menggunakan pendekatan cross sectional survey yaitu penelitian yang pengumpulan datanya dilakukan dalam satu kali pengambilan. Penelitian dilakukan pada siswa kelas 4 dan 5 SD Negeri Babad 1 sebanyak 31 orang siswa. Teknik pengumpulan data menggunakan skala rating untuk mengetahui pola tidur siswa dan studi dokumen digunakan untuk mengetahui prestasi belajar siswa. Dokumen yang digunakan adalah rata-rata nilai Rapor Semester 1.

\section{HASIL PENELITIAN DAN PEMBAHASAN}

Penelitian ini menghasilkan data seperti pada tabel 1 berikut:

Tabel 1. pola tidur

\begin{tabular}{c|c|c}
\hline $\begin{array}{c}\text { Pola } \\
\text { Tidur }\end{array}$ & $\begin{array}{c}\text { Frekuensi } \\
(\mathbf{n})\end{array}$ & $\begin{array}{c}\text { Persentase } \\
(\%)\end{array}$ \\
\hline Baik & 26 & 84 \\
\hline $\begin{array}{c}\text { Kurang } \\
\text { Baik }\end{array}$ & 5 & 16 \\
\hline TOTAL & 31 & 100 \\
\hline
\end{tabular}

Beradasarkan Tabel 1 bahwa dari 31 siswa terdapat 26 siswa dengan persentase $84 \%$ yang memiliki pola tidur yang baik, serta 5 siswa dengan persentase $16 \%$ memiliki pola tidur yang kurang baik.

Tabel 2. prestasi belajar

\begin{tabular}{c|c|c}
\hline $\begin{array}{c}\text { Prestasi } \\
\text { Belajar }\end{array}$ & $\begin{array}{c}\text { Frekuensi } \\
(\mathbf{n})\end{array}$ & $\begin{array}{c}\text { Persentase } \\
(\%)\end{array}$ \\
\hline Baik & 19 & 61 \\
\hline $\begin{array}{c}\text { Cukup } \\
\text { Baik }\end{array}$ & 12 & 39 \\
\hline TOTAL & 31 & 100 \\
\hline
\end{tabular}


Berdasarkan Tabel 2 bahwa dari 31 siswa terdapat 19 siswa dengan persentase $61 \%$ yang memiliki prestasi belajar yang baik, serta 12 siswa dengan persentase $39 \%$ memiliki prestasi belajar yang cukup baik.

Tabel 3. hubungan pola tidur dengan prestasi belajar

\begin{tabular}{l|l|l}
\hline \multicolumn{1}{c|}{ KET. } & $\begin{array}{c}\text { Frekue } \\
\text { nsi } \\
(\mathbf{n})\end{array}$ & $\begin{array}{c}\text { Persen } \\
(\%)\end{array}$ \\
\hline $\begin{array}{l}\text { Pola Tidur Baik } \\
\text { serta Prestasi } \\
\text { Belajar Baik }\end{array}$ & 18 & $58 \%$ \\
\hline $\begin{array}{l}\text { Pola Tidur Baik } \\
\text { serta Prestasi } \\
\text { Belajar Cukup Baik }\end{array}$ & 8 & $26 \%$ \\
\hline $\begin{array}{l}\text { Pola Tidur Kurang } \\
\text { Baik serta Prestasi } \\
\text { Belajar Baik }\end{array}$ & 1 & $3 \%$ \\
\hline $\begin{array}{l}\text { Pola Tidur Kurang } \\
\text { Baik serta Prestasi } \\
\text { Belajar Cukup Baik }\end{array}$ & 4 & $13 \%$ \\
\hline TOTAL & 31 & $100 \%$ \\
\hline
\end{tabular}

Berdasarkan Diagram 1,siswa yang memiliki pola tidur baik menunjukan 18 siswa dengan persentase $58 \%$ memiliki prestasi yang baik serta 8 siswa dengan persentase $26 \%$ memiliki prestasi belajar yang cukup baik. Siswa yang memiliki pola tidur kurang baik menunjukan 1 siswa dengan persentase $3 \%$ memiliki prestasi belajar yanga baik serta 4 siswa dengan persentase $13 \%$ memiliki prestasi yang cukup baik. Berdasarkan penelitian ini maka terdapat pengaruh hubungan antara pola tidur terhadap prestasi belajar siswa.
Tabel 4. analisis uji hubungan antara pola tidur dengan prestasi belajar

\begin{tabular}{|c|c|c|c|}
\hline \multicolumn{4}{|c|}{ Correlations } \\
\hline & & pola & prestasi \\
\hline & & Tidur & belajar \\
\hline \multirow{6}{*}{$\begin{array}{l}\text { pola } \\
\text { Tidur }\end{array}$} & Pearson & 1 & $397^{*}$ \\
\hline & Correlation & & \\
\hline & $\begin{array}{l}\text { Sig. }(2- \\
\text { tailed })\end{array}$ & & .027 \\
\hline & $\begin{array}{c}\text { Sum of } \\
\text { Squares } \\
\text { and Cross- } \\
\text { products }\end{array}$ & 65.097 & 65.742 \\
\hline & Covariance & 2.170 & 2.191 \\
\hline & $\mathrm{N}$ & 31 & 31 \\
\hline \multirow[t]{5}{*}{$\begin{array}{l}\text { prestasi } \\
\text { belajar }\end{array}$} & $\begin{array}{l}\text { Pearson } \\
\text { Correlation }\end{array}$ & $.397^{*}$ & 1 \\
\hline & $\begin{array}{l}\text { Sig. (2- } \\
\text { tailed) }\end{array}$ & .027 & \\
\hline & $\begin{array}{c}\text { Sum of } \\
\text { Squares } \\
\text { and Cross- } \\
\text { products }\end{array}$ & 65.742 & 421.355 \\
\hline & Covariance & 2.191 & 14.045 \\
\hline & $\mathrm{N}$ & 31 & 31 \\
\hline \multicolumn{4}{|c|}{$\begin{array}{c}* \text {. Correlation is significant at the } 0.05 \\
\text { level (2-tailed). }\end{array}$} \\
\hline
\end{tabular}

Berdasarkan hasil uji statistik, diketahui bahwa terdapat hubungan yang signifikan antara pola tidur dengan prestasi belajar. Sehingga terdapat pengaruh hubungan antara pola tidur terhadap prestasi belajar siswa. Pola tidur memang tidak secara langsung berpengaruh kepada prestasi belajar. Melainkan akan berpengaruh pada aspek yang lain terlebih dahulu. Jika anak memiliki pola tidur yang kurang baik maka akan mempengaruhi aktivitas dan kondisi siswa. Misalnya saja, ketika di sekolah siswa mudah mengantuk dan menyebabkan tidak konsentrasi dalam 
belajar. Dalam kondisi seperti ini, siswa kemungkinan tidak mengikuti proses belajar dengan baik dan akan berpengaruh terhadap nilai. Karena jika anak tidak mengikuti proses belajar dengan baik, akan membuat anak sulit memahami materi. Ketika ada tugas atau ulangan atau bahkan tes, pada umumnya anak akan merasa kesulitan untuk mengerjakan dan pada akhirnya nilai yang didapatkan tidak sesuai dengan keinginan. Sebaliknya, jika anak memiliki pola tidur yang baik dan aktivitas belajarnya tidak terganggu maka kemungkinan anak mengalami kesulitan dalam mengerjakan sesuatu akan terminimalisir.

Penelitian yang dilakukan oleh Jaka Sarfriyanda, Darwin Karim, dan Ari Pristiana Dewi (2015), menunjukkan hasil penelitian tentang hubungan kualitas tidur dan kuantitas tidur dengan prestasi belajar mahasiswa, diketahui bahwa responden memiliki kualitas tidur yang baik hanya $32(17,8 \%)$ orang dan responden yang memiliki kuantitas tidur yang buruk sebanyak $162(82,2 \%)$. Untuk kuantitas tidur diperoleh jumlah mahasiswa yang memiliki kuantitas tidur yang cukup dan kuantitas tidur kurang hampir sama, yaitu $95(48,2 \%)$ orang untuk kuantitas tidur yang cukup dan 102 $(51,8 \%)$ orang yang memiliki kuantitas tidur yang kurang. Berdasarkan hasil uji statistik dapat disimpulkan bahwa tidak ada hubungan antara kualitas tidur dengan prestasi belajar ( $\mathrm{p}$ value: 0,284 > $0,05)$, dan tidak ada hubungan kuantitas tidur dengan prestasi belajar ( $\mathrm{p}$ value : 0,244 >0,05).

Berbeda dengan penelitian diatas, penelitian yang telah dilakukan oleh Panangian P. Marpaung, Siantan Supit, dan Joice Nancy (2013) menyatakan bahwa siswa yang cukup tidur memiliki prestasi belajar yang tinggi yaitu sebesar 49,1\%. Selain itu, berdasarkan penelitian yang dilakukan oleh Aria Ahdi Winara (2016) menyatakan bahwasiswa yang memiliki kualitas tidur baik sebagian besar memiliki prestasi belajar baik sebanyak 47 orang $(26,1 \%)$. Adapun siswa yang memiliki kualitas tidur baik ternyata memiliki prestasi belajar yang rendah sebanyak 1 orang $(0,6 \%)$. Siswa yang memiliki kualitas tidur buruk ternyata sebagian besar juga memiliki prestasi belajar yang cukup yaitu sebanyak 56 orang $(31,1 \%)$, dan yang memiliki prestasi belajar yang rendah sebanyak 4 orang $(2,2 \%)$. Hasil perhitungan statistik menggunakan uji kendall's Tau diperoleh p-value sebesar $0,004<\alpha$ $(0,05)$, sehingga dapat disimpulkan bahwa ada hubungan antara kualitas tidur dengan prestasi belajar siswa. Begitu juga dalam penelitian ini, terbukti bahwa siswa yang memiliki pola tidur yang baik juga memiliki prestasi belajar yang baik yaitu mencapai 58\%. Penelitian yang telah dilakukan oleh Mander B dan Walker M (2014) menyatakan bahwa banyak orang yang tidak menghiraukan pola tidur, padahal tubuh membutuhkan waktu untuk beristirahat. Waktu istirahat yang kurang akan berpengaruh ke otak. Tidur memiliki 
peranan yang penting bagi otak, diantaranya adalah: (1) membantu otak bekerja dengan baik. Selama tidur, otak akan memperbaiki kelelahan, kekebalan tubuh, ingatan, dan konsentrasi. Kekebalan tubuh ini berpengaruh terhadap kesehatan; (2) tidur berkaitan dengan proses mengingat, karena tidur dapat meningkatkan perubahan yang terjadi diantara sel-sel saraf di otak. Perubahan tersebut berkaitan dengan perilaku, belajar, dan mengingat; dan

(3) tidur dapat mencerna ulang, memahami, mengingat, dan memproses apa yang telah diterima oleh otak, baik berupa pengalaman ataupun materi. Kelemahan otak dalam mencerna ulang pengalaman pada saat kurang tidur dapat berpengaruh terhadap prestasi belajar.

\section{Pembahasan}

Penelitian yang telah membuktikan bahwa terdapat hubungan antara pola tidur dengan prestasi belajar dikuatkan dengan penjelasan berikut ini. Jumlah kebutuhan tidur kurang dari 10 jam termasuk ke dalam pola tidur yang buruk. Jika kurang tidur, maka akan berpengaruh ke otak dan menyebabkan konsentrasi belajar terganggu. Anak yang mengalami hambatan dalam proses belajar disebabkan oleh rasa mengantuk dan lelah akibat kurang tidur, sehingga konsentrasi belajar menurun. Hal ini membuat anak akan mengalami gangguan dalam belajar, menjadi pelupa, sulit untuk berkonsentrasi, sulit untuk mencerna materi yang telah didapatkan, sulit untuk menerima pelajaran baru, sukar untuk memperhatikan pelajaran yang disampaikan, dan sulit untuk mengerjakan soal. Faktor-faktor tersebut berdampak kepada menurunnya kemampuan untuk berkonsentrasi dan berpartisipasi dalam kegiatan sehari-hari sehingga menyebabkan penurunan prestasi belajar.

\section{SIMPULAN}

Hasil dari penilitian ini adalah siswa yang memiliki pola tidur yang baik dan prestasinya juga baik jumlahnya lebih banyak yaitu 18 siswa (58\%) dibandingkan dengan siswa yang memiliki pola tidur baik tetapi prestasi belajarnya cukup yaitu 8 siswa (26\%). Namun, ada pula yang memiliki pola tidur yang kurang baik. Siswa dengan prestasi belajar yang cukup lebih banyak jumlahnya yaitu 4 siswa (13\%) dibandingkan dengan siswa yang memiliki prestasi belajar baik hanya ada 1 siswa (3\%). Pada umumnya, siswa yang memiliki pola tidur baik akan mempunyai prestasi belajar yang baik pula. Berdasarkan hasil penelitian dan pembahasan, maka dapat disimpulkan bahwa terdapat hubungan antara pola tidur dengan prestasi belajar siswa.

Penelitian ini dapat menjadi informasi sekaligus masukan bagi guru dan orang tua. Bagi guru khususnya untuk guru Sekolah Dasar yang nantinya akan menjadi seorang wali kelas, diharapkan dapat mengenali karakteristik setiap siswanya. Baik dari segi sikap, latar 
belakang siswa, dan prestasi yang diperoleh. Guru dapat melakukan pendekatan atau konseling untuk mengetahui pola tidur dari siswa agar guru dapat mengetahui perkembangan siswa. Sedangkan bagi orang tua siswa, diharapkan dapat mengetahui dan mengontrol pola tidur anak. Agar anak dapat memiliki pola tidur yang baik dan membuat prestasi belajar anak menjadi semakin meningkat.

\section{DAFTAR RUJUKAN}

Marpaung, P. P., Supit, S., \& Nancy, J. 2013. Gambaran Lama Tidur Terhadap Prestasi Belajar Siswa. Jurnal e-Biomedik, 1 (1). Nilifda, H., Nadjmir, N., \& Hardisman, H. 2016. Hubungan Kualitas Tidur dengan Prestasi Akademik Mahasiswa Program Studi Pendidikan Dokter Angkatan 2010 FK Universitas Andalas. Jurnal Kesehatan Andalas, 5 (1).

Purwanto. 2007. Instrumen penelitian sosial dan pendidikan: pengembangan dan pemanfaatan. Pustaka Pelajar.

Putri, A. A., \& Ruhyana, R. 2012. Hubungan antara Kualitas Tidur dengan Konsentrasi Belajar dan Indeks Prestasi Mahasiswa Program DIII Kebidanan STIKES 'Aisyiyah Yogyakarta (Doctoral dissertation, STIKES 'Aisyiyah Yogyakarta).

Sarfriyanda, J., Karim, D., \& Dewi, A. P. 2015. Hubungan Antara Kualitas Tidur Dan Kuantitas Tidur Dengan Prestasi Belajar
Mahasiswa. Jurnal Online Mahasiswa Program Studi Ilmu Keperawatan Universitas Riau, 2 (2), 1178-1185.

Sobur A. 2006. Psikologi Umum. Bandung: Pustaka Setia.

Susanto H. 2013. Meningkatkan konsentrasi siswa melalui optimalisasi modalitas belajar siswa (diunduh 10 Juli 2013). Tersedia dari: URL: HYPERLINKhttp://www.bpkpen abur.or.id.

Walker, M. B. (2014, February 21). Kualitas tidur dan usia mempengaruhi tugas mengingat otak. Retrieved from Mediapubli ca.co: http://www.Mediapubli ca.co.

Winara, A. A. 2016. Hubungan antara Kualitas Tidur dengan Prestasi Belajar Siswa di SMPN 2 Bantul Daerah Istimewa Yogyakarta (Doctoral dissertation, STIKES Jenderal A. Yani Yogyakarta). 